\title{
Shiga-Like Toxin-Producing Escherichia coli Inducing Diarrhea in Patients with Multiple Myeloma Diagnosed by BioFire PCR-Film Array
}

\author{
Natalia Kreiniz ${ }^{a}$ Asala Abu-Ahmad ${ }^{b}$ Orit Golan-Shany ${ }^{c}$ Alona Paz ${ }^{b}$ Tamar Tadmor $^{a}$ d \\ ${ }^{a}$ Hematology Unit, Bnai Zion Medical Center, Haifa, Israel; ${ }^{\mathrm{b}}$ Infectious Disease Unit, Bnai Zion Medical Center, Haifa, \\ Israel; ' Microbiology Laboratory, Bnai Zion Medical Center, Haifa, Israel; ${ }^{\mathrm{d}}$ The Ruth and Bruce Rappaport Faculty of \\ Medicine, Technion, Haifa, Israel
}

Here we present the first report of 3 patients with multiple myeloma (MM) who had Shiga-like toxin-producing Escherichia coli as a cause of their diarrhea, detected by Film Array PCR-gastrointestinal (GI) panel.

Infections are a major cause of morbidity in $\mathrm{MM}$, and one of the most frequent of these is gastroenteritis developing because of immune paresis in MM and immunosuppression linked to therapies administered [1]. Correct diagnosis and early identification of a GI pathogen, followed by correct therapeutic intervention, may have clinical significance for patients with MM. Routine evaluation of these patients requiring hospitalization due to diarrhea include standard culture methods which have a turnaround period up to 3 days. However, newer molecular diagnostics can reduce the time taken for results and provide more accurate diagnosis. It is noteworthy that there are limited routine testing methods available for most strains of $E$. coli causing diarrhea.

The FilmArray GI panel is a relatively new method introduced recently, which provides simultaneous detection of 22 different enteric pathogens on stool speci- mens with a turnaround time as short as $1 \mathrm{~h}$ [2]. Because it is costly, it is not used routinely in all patients presenting to the emergency room with acute diarrhea.

Alejo-Cancho et al. [3] conducted a prospective observational study to compare conventional methods for the diagnosis of infectious diarrhea with the FilmArray GI panel in immunocompromised hematologic patients diagnosed with acute diarrhea. In their study, 95 patients were evaluated, and 25 (26\%) patients had a positive microbiological result, with Clostridium difficile being the most frequent pathogen. The concordance between FilmArray methods was good, but the time required to obtain results was markedly reduced with the use of multiplex PCR methods.

In another study, Freeman et al. [4] systematically reviewed the evidence for multiplex GI pathogen panel tests and concluded that these tests will generally correctly identify pathogens identified by conventional testing; however, they also generate considerable additional positive results of uncertain clinical importance.

We summarize the results of the FilmArray GI panel obtained in 4 MM patients hospitalized and treated at our institute in
2018 because of acute diarrhea who had positive PCR-Biofire results (Table 1; Fig. 1).

This GI panel includes the following pathogens: Campylobacter, Clostridium difficile, Plesiomonas shigelloides, Salmonella, Vibrio, Yersinia enterocolitica, enteroaggregative $E$. coli, enteropathogenic E. coli, enterotoxigenic E. coli, Shiga-like toxin-producing E. coli (including E. coli O157), Shigella, Cryptosporidium, Cyclospora cayetanensis, Entamoeba histolytica, Giardia lamblia, adenovirus F 40/41, astrovirus, norovirus $\mathrm{GI} / \mathrm{GII}$, rotavirus $\mathrm{A}$, and sapovirus.

All patients examined had relapsed/refractory MM and had received 2-5 lines of anti-MM therapy. One patient presented with 2 different episodes of acute diarrhea and was evaluated twice.

All 4 patients had low IgA levels, which is known to be a major immunoglobulin on mucosal surfaces that protects the bowel from pathogens invasion, particularly Shiga toxin [5]. Five pathogens were detected: STEC (Shiga-like toxin producing E. coli) was the most common and was detected 3 times; EPEC (enteropathogenic E. coli) and ETEC (enterotoxigenic E. coli) were detect- 
Fig. 1. Abdominal CT scans showing severe colitis in a patient with relapsed myeloma (arrows pointing towards inflamed colon).
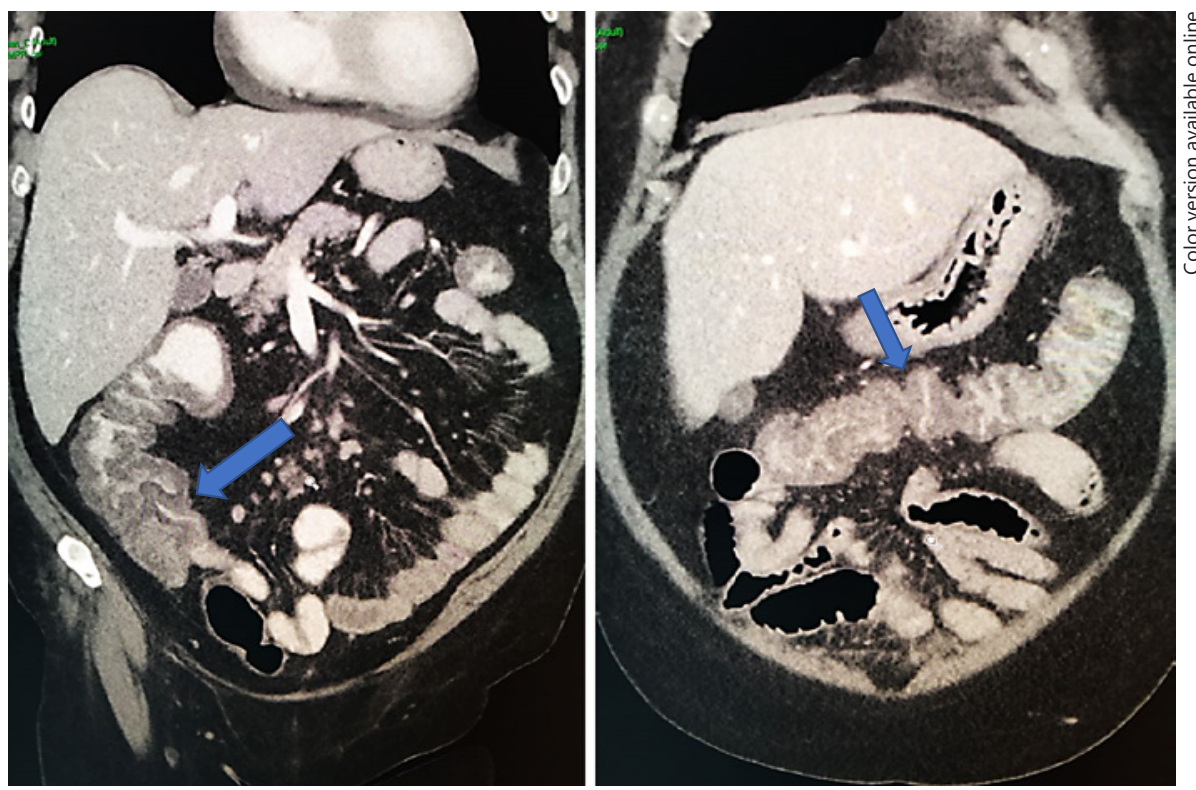

Table 1. Patients with multiple myeloma (MM) and acute diarrhea, evaluated by BioFire FilmArray: characteristics and outcomes

\begin{tabular}{|c|c|c|c|c|c|c|c|c|c|c|c|c|}
\hline $\begin{array}{l}\text { Age, } \\
\text { years }\end{array}$ & Sex & MM & $\begin{array}{l}\text { Treat- } \\
\text { ments, } n\end{array}$ & $\begin{array}{l}\text { Current treatment } \\
\text { protocol }\end{array}$ & $\begin{array}{l}\text { Diarrhea } \\
\text { diagnosis }\end{array}$ & $\begin{array}{l}\text { Pathogen } \\
\text { on BioFire }\end{array}$ & $\begin{array}{l}\text { ANC, } \\
\times 10^{3 /} \mathrm{mm}^{3}\end{array}$ & $\begin{array}{l}\mathrm{IgG} \\
\mathrm{mg} / \mathrm{dL}\end{array}$ & $\begin{array}{l}\mathrm{IgM} \text {, } \\
\mathrm{mg} / \mathrm{dL}\end{array}$ & $\begin{array}{l}\mathrm{IgA} \\
\mathrm{mg} / \mathrm{dL}\end{array}$ & $\begin{array}{l}\text { Anti- } \\
\text { biotic }\end{array}$ & Outcome \\
\hline 78 & $\mathrm{~F}$ & $\mathrm{RR}$ & 3 & VCD & $\begin{array}{l}\text { GE } \\
\text { Colitis }\end{array}$ & EPEC & 7.87 & 2,850 & 26 & 35 & AZM & Improved \\
\hline 53 & M & $\mathrm{RR}$ & 4 & POM/DEX & GE & $\begin{array}{l}\text { STEC } \\
\text { ETEC }\end{array}$ & 0.16 & 320 & 29 & 27 & AZM & Improved \\
\hline 65 & M & $\mathrm{RR}$ & 2 & KRD & Diarrhea & STEC & 0.87 & 2,490 & $<174$ & 33 & $\mathrm{AZM}$ & Improved \\
\hline 53 & $\mathrm{~F}$ & $\mathrm{RR}$ & 2 & DRD & $\begin{array}{l}\text { GE } \\
\text { Colitis }\end{array}$ & $\begin{array}{l}\text { STEC } \\
\text { E. coli } \\
0157\end{array}$ & 3.7 & 267 & 34 & 14.9 & AZM & Improved \\
\hline 53 & M & $\mathrm{RR}$ & 5 & No treatment & Diarrhea & EPEC & 7.59 & 320 & 29 & 27 & $\mathrm{AZM}$ & Improved \\
\hline
\end{tabular}

RR, relapsed refractory; VCD, Velcade, cyclophosphamide, dexamethasone; POM/DEX, pomalidomide, dexamethasone; KRD, Kyprolis, Revlimid, dexamethasone; DRD, daratumumab, Revlimid, dexamethasone; EPEC, enteropathogenic E. coli; STEC, Shiga-like toxin-producing E. coli; ETEC, enterotoxigenic E. coli; ANC, absolute neutrophil count; AZM, azithromycin; GE, gastroenteritis.

ed one time each. All patients received antibiotics (azithromycin) and improved.

Careful review of the literature did not identify any documented report of MM patients with Shiga-like toxin-producing E. coli.

We conclude that the Biofire assay can identify new pathogens responsible for diarrhea that had not been identified earlier or in cases treated routinely after employing the regular culture method. It may affect the therapeutic approach since antibiotic therapy in STEC is not beneficial and was even associated with the development of the hemolytic uremic syndrome in some studies.

Based on the above results, there is a need for more clinical experience, using the Biofire FilmArray as a diagnostic test for immunocompromised patients with MM and other hematological malignancies.

\section{Statement of Ethics}

The anonymity and confidentiality of the patients reported in this paper is provided as required.

\section{Disclosure Statement}

The authors have no conflicts of interest to declare.

\section{Funding Sources}

There were no funding sources for this study.

Kreiniz/Abu-Ahmad/Golan-Shany/Paz/ Tadmor 


\section{References}

1 Schutt P, Brandhorst D, Stellberg W, Poser M, Ebeling P, Muller S, et al. Therapy-Associated Immunosuppression and Opportunistic Infections in Multiple Myeloma Patients. Am Soc Hematol. 2005:5137.

2 Buss SN, Leber A, Chapin K, Fey PD, Bankowski MJ, Jones MK, et al. Multicenter evaluation of the BioFire FilmArray gastrointestinal panel for the etiologic diagnosis of infectious gastroenteritis. J Clin Microbiol. 2015 Mar;53(3):915-25.
3 Alejo-Cancho I, Fernández Avilés F, Capón A, Rodríguez C, Barrachina J, Salvador P, et al. Evaluation of a multiplex panel for the diagnosis of acute infectious diarrhea in immunocompromised hematologic patients. PLoS One. 2017 Nov; 12(11):e0187458.

4 Freeman K, Mistry H, Tsertsvadze A, Royle P, McCarthy N, Taylor-Phillips S, et al. Multiplex tests to identify gastrointestinal bacteria, viruses and parasites in people with suspected infectious gastroenteritis: a systematic review and economic analysis. Health Technol Assess. 2017 Apr;21(23):1-188.
5 Nakanishi K, Morikane S, Ichikawa S, Kurohane K, Niwa Y, Akimoto Y, et al. Protection of human colon cells from Shiga toxin by plant-based recombinant secretory IgA. Sci Rep. 2017 Apr;7(1):45843. 